


\title{
Como as democracias (não) morrem
}

\author{
Thais Ferreira Rodrigues
}

Doutoranda em Ciência Política pelo Programa de Pós Graduação em Ciência Política (PPGCP) da Universidade Federal Fluminense (UFF).

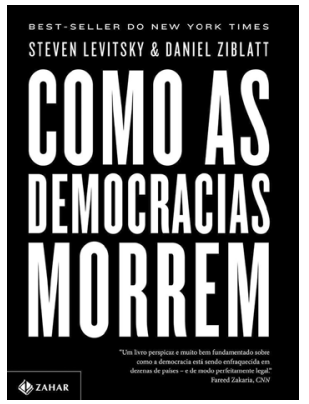

Em tempos de informações e discussões pautadas por caracteres limitados e algoritmos definidores de bolhas ideológicas, ter um livro de ciência política na lista dos mais vendidos nos EUA, Brasil e Alemanha traz o debate sobre uma possível crise democrática para a ordem do dia e em outro patamar teórico. Escrito por dois professores de Ciência Política da Harvard University, Steven Levitsy e Daniel Ziblatt, o livro "Como as democracias morrem" (2018) parte de um questionamento inicial: por que depois de décadas de avanço, vivemos uma recessão democrática? E mais, como até mesmo os EUA, país detentor de uma democracia até então sólida, não está imune a isso ao ter possibilitado a vitória de Donald Trump nas eleições de 2016? Apesar de não ter iniciado com Trump, o questionamento acerca da deterioração da democracia americana se acentua com sua ascensão ao poder, tendo em vista que é a primeira vez na história dos EUA que um outsider político com características autoritárias consegue se estabelecer deixando um rastro de consequências políticas que são analisadas.

Os autores concentram seus estudos em debates sobre partidos políticos e sistemas partidários, autoritarismos, transição de regimes políticos e processos de democratização, além de instituições políticas informais na América Latina, no caso de Levitsy e na Europa do séc XIX aos dias atuais, no caso de Ziblatt. Essa bagagem teórica faz com que análises de enfraquecimento das democracias ao redor do mundo na atualidade sejam utilizadas, comparando-as com casos do passado, sempre que pertinente. No entanto, o foco é a democracia americana a partir de descrição de sua formação, momentos de crise e como o sistema de freios e contrapesos da Constituição dos EUA, bem como as regras não escritas, serviram para defender a manutenção da democracia mais antiga do mundo moderno, o que foi colocado em perigo com a eleição de Trump. As saídas apontadas ao final do livro abrem caminho para uma discussão entre os argumentos trazidos por Mark Lilla no livro "O Progressista de ontem e do amanhã: desafios da democracia liberal no mundo pós políticas identitárias" (2018) sobre as responsabilidades do partido democrata em ter perdido a eleição presidencial em 2016 ao priorizar o que ele chama de pautas identitárias, e as eleições de meio de mandato ocorridas em 2018, cujos resultados trazem mais questões ao que foi discutido pelos autores nas obras citadas. 
Logo no início, os autores apresentam a tese de que as democracias não morrem mais apenas pela via da violência, como ocorria no séc. XX. Imagens de militares derrubando governos civis com seus canhões se tornaram obsoletas, e, hoje, "o retrocesso democrático começaria nas urnas" (p.16). Os líderes autoritários que matam lentamente as democracias modernas chegam ao poder através de eleições e, a partir de então, utilizam a lei em benefício próprio, expandindo sua autoridade e se perpetuando no poder por meio de um verniz de legitimidade e normalidade das instituições. Paradoxalmente, é a própria democracia que leva ao seu fim quando seus mecanismos de defesa não se mostram efetivos para impedirem a ascensão de autocratas.

No caso norte-americano, e em outros exemplos históricos ressaltados como Hitler na Alemanha, Mussolini na Itália e Fujimori no Peru, não são políticos tradicionais que assumem esse papel, mas sim outsiders que assumem um discurso anti-establishment e conseguem respaldo na população para tal. Nem sempre esses líderes demonstram traços autoritários num primeiro momento e de forma explícita, porém Levitsy e Ziblatt elaboraram uma tipologia de comportamentos com os quais deve-se ficar alerta - tais pontos foram desenvolvidos a partir da obra de outro cientista político, Juan Linz, "The breakdown of democracies" (1978). Ressaltam que não é necessário que o político analisado apresente os quatro indicadores, porém quanto mais características exibirem, maior o risco para a democracia. São eles: (1) rejeição às regras do jogo democrático, basicamente quando candidatos rejeitam a Constituição, propõem restringir os direitos civis e políticos, endossam meios extra constitucionais para modificar o governo, como golpes e insurreições violentas e deslegitimam o processo eleitoral, recusando-se a aceitar os resultados eleitorais ou alegando fraude; (2) negação da legitimidade dos oponentes políticos, acusando-os de subversão, de serem criminosos, ou até de não amarem o país, colaborando com governos estrangeiros; (3) tolerância e encorajamento à violência, através de laços com gangues armadas, milícias ou guerrilhas, ou elogios a atos significativos de violência política; (4) propensão a restringir liberdades civis através de medidas autoritárias que reduzam liberdades de imprensa e de adversários. Donald Trump preenche todos os requisitos, o que segundo os autores é motivo de grande preocupação.

Subestimare darvoza personalidadescom discursosautoritárioseantidemocráticos são passos fundamentais para que democracias morram ao redor do mundo. Os autores se questionam, então, como elas conseguem transformar essa notoriedade em vitória eleitoral em regimes democráticos. Não é obrigatório que exista uma crise para que surjam, mas são em contextos de crises econômicas, políticas e sociais que ganham espaço. Através de discursos ultranacionalistas e com viés autoritários, além de se colocarem contra corrupção e a "velha forma de se fazer política", atraem a atenção do eleitorado descontente com a situação dos países. Importante ressaltar que neste ponto os autores não responsabilizam os eleitores por embarcarem nesses discursos, pois, principalmente em momentos de crise, estes anseiam por algo que, 
aparentemente, resolvam suas demandas de imediato. Ou até mesmo em momentos de mudanças estruturais, ao prometerem manter as coisas como eram anteriormente, demagogos costumam carregar seus discursos com altas doses de moralidade que encontram respaldo em um eleitorado conservador. No entanto, as elites políticas e econômicas são as maiores responsáveis ao se aliarem a essas figuras no intuito de aproveitarem a popularidade e atraírem mais votos. Iludem-se de que ao chegarem ao poder conseguirão controlá-los e submetê-los ao status quo. A experiência histórica mostra que isso não acontece.

Mais uma vez recorrendo ao padrão de comportamento dos autocratas em outros países e momentos históricos, os autores trazem três métodos que acentuam o processo de desintegração da democracia. O primeiro seria a captura dos árbitros, em que juízes aliados passam a compor a maioria nos tribunais superiores fazendo com que os atos do poder executivo tenham caráter de legalidade. Conseguindo subjugar o judiciário, em seguida passa-se a neutralizar a oposição reduzindo as possibilidades de dissenso e questionamento das ações governamentais. Por fim, são reescritas regras que regulam as eleições ou a atuação dos demais poderes. Pode-se convocar assembleias ou reformas constitucionais e mudanças de regras eleitorais no intuito de garantir maiorias nas casas legislativas.

Ao se aliarem a autocratas por interesses próprios, as elites contradizem princípios democráticos básicos, denominados "regras não-escritas da política" pelos autores, como a tolerância mútua e a reserva institucional. Apesar da Constituição dos EUA ser reconhecida como um dos fatores principais para a manutenção e estabelecimento da democracia por tanto tempo, existem outras importantes normas estabelecidas que também asseguram a democracia. A diluição dessas regras acarreta uma maior hostilidade ao cenário político, com maior ataque entre governo e oposição e ampliação do uso de poderes constitucionais, o que é chamado de "jogo duro constitucional". A atitude dos políticos acaba ecoando no povo, logo, quando as regras não escritas são violadas reiteradamente, as sociedades tendem a "diluir a definição de desvio comportamental". O que antes era visto como anormal se torna normal, o que contribui ainda mais para o enfraquecimento da democracia.

A tolerância mútua consiste, basicamente, em tratar a divergência como adversária, mas não como inimiga. As discordâncias entre opositores devem ser feitas, porém, através do reconhecimento da legitimidade de seus posicionamentos. Isso faz com que seja possível evitar uma polarização extrema que inviabiliza o diálogo e a cooperação, imprescindíveis numa democracia. A reserva institucional, por sua vez, é o uso moderado dos dispositivos constitucionais para que os freios e contrapesos entre os poderes funcionem de forma harmônica. Quando se opta por interpretar os dispositivos constitucionais ao pé da letra de forma intencional para que se legitime abusos de um poder sobre o outro, tem-se a legitimidade do procedimento técnico, mas uma violação do "espírito" em que os princípios da constituição foram escritos. 
Sendo assim, após descreverem formas de identificar a ascensão de autocratas e as etapas que levam à morte das democracias modernas, todas preenchidas por Donald Trump, os autores apontam caminhos para que se evite que aconteça no futuro ou para que se minimize os danos no presente. Segundo discorrem, os partidos políticos são os legítimos guardiões da democracia, na medida em que são os responsáveis por escolherem os candidatos que concorrerão aos cargos públicos. É recomendado um processo seletivo rigoroso que impossibilite indivíduos despreparados e com discursos autoritários de serem eleitos, criando assim uma grade de proteção. No caso de Trump, considerado um outsider com poucos contatos na política, foi possível burlar os freios impostos pelo sistema partidário norte americano e se candidatar a partir do momento em que foi implementado pelo Partido Republicano, do qual faz parte, o sistema de primárias presidenciais vinculantes, retirando o controle da indicação dos candidatos à presidência dos chefes partidários.

Por último, Levisty e Ziblatt ressaltam que a explicação para a morte da democracia perpassa pela escolha de indivíduos em violar normas e pela falha de outros em impedir ou neutralizar essas ações. Assim como democracias são reversíveis e um meio para sua própria morte, é no aprofundamento da democracia que está a saída para sua crise. Os autores conclamam um pacto entre as divergências em favor da democracia para evitar que o autoritarismo chegue ao poder e caso não seja possível, que se organizem bancadas democráticas que impeçam a usurpação do Estado, que os poderes legislativos e judiciário vigiem e cobrem o executivo. E que a restauração das normas de tolerância e reserva mútua sejam o caminho e o fim, formando coalizões entre diferentes atores com o objetivo de preservar a democracia.

Assim como Levitsky e Ziblatt, Mark Lilla, professor da Universidade de Columbia e autor do livro "O progressista de ontem e o do amanhã: desafios da democracia liberal no mundo pós políticas identitárias" (2018) recorre a exemplos históricos da política americana para entender como os partidos políticos permitiram e em que medida são responsáveis pela ascensão de Donald Trump ao poder. Porém, ao contrário dos primeiros autores citados que responsabilizam ambos os partidos pela vitória de Trump, o Partido Republicano por ter permitido que ele se candidatasse e com isso rompido algumas regras políticas até então vigentes e o Partido Democrata por não ter conseguido se apresentar como uma opção viável ou feito uma coalização que protegesse a democracia de tendências autoritárias, Lilla foca sua atenção e suas críticas ao segundo, do qual é filiado. Para ele, o Partido Democrata não foi capaz de propor alguma narrativa que resgatasse um sentido de unidade entre os norteamericanos, algo que fosse comum, como a cidadania, em detrimento de pautas identitárias que teriam levado a uma divisão entre os segmentos da população que passaram a advogar somente em causas próprias deixando de lado o coletivo, abrindo espaço para que o Partido Republicano aglutinasse aqueles que não se identificavam com esses novos discursos e assim fosse possível a vitória de Trump. 
O grande equívoco apontado pelo autor reside na opção por políticas identitárias e hipersensíveis feita pelos democratas em detrimento de uma outra, voltada aos valores fundamentais que deveriam ser difundidos pelos liberais. Teria acontecido uma abdicação de uma visão verdadeiramente política que dialogasse com uma ampla tradição de defesa de igualdade de oportunidades e de direitos de todos os indivíduos pelo simples fato de que qualquer um é um cidadão. Optar por um discurso interseccional e voltado para minorias seria eficaz em criar polêmicas que serviriam ao aglutinamento dos indivíduos em seus grupos identitários, mas que não seria capaz de ganhar eleição, o que ele considera o mais importante quando se trata de ação política.

A esse fenômeno de busca por políticas identitárias, Lilla chama de uma "abordagem antipolítica", em que os indivíduos, ao olharem mais para si mesmos do que para os outros, se tornam ressentidos, assim como são incapazes de perceber quais valores que levaram, ao longo da história do país, lideranças a oferecerem aquilo que representaria o liberalismo americano: uma cidadania amparada em direitos que qualquer norte-americano, independentemente de sua origem étnica e social, de sua condição econômica e seus estilos e preferências, pudesse chamar de sua. Com um certo exagero, alega que os indivíduos estão sendo hipnotizados por símbolos que buscam alcançar diversidade superficial nas organizações, reformulação da história focando em grupos marginais e mesmo minúsculos, invenção de eufemismos inofensivos para descrever a realidade social, assim como evitam qualquer encontro que confronte pontos de vista alternativos. Ou seja, a insistência na narrativa identitária, o que teria sido apropriado pelo Partido Democrata durante as eleições de 2016, estimula a formação de indivíduos que, ao olharem e valorizarem apenas as suas aparentes diferenças, não se voltam ao resgate dos valores os unem. Com isso, causaria mais repulsa do que empatia, e reforçaria o ressentimento entre os diferentes grupos que prefeririam professar o discurso de resistência a um discurso propositivo, o que ele chama de antipolítica em detrimento da política.

Passados dois anos após as eleições de 2016, e um ano depois do lançamento de ambos os livros, apêndices seriam indicados em novas edições. A polarização continua acentuada nos EUA, assim como a democracia continua enfraquecida com os frequentes desrespeitos do presidente a ela, porém ela ainda continua viva. Nas eleições de meio de mandato no ano de 2018, o Partido Democrata conseguiu maioria na Câmara, enquanto o Partido Republicano se manteve no Senado. Ao contrário do que Mark Lilla argumentava, mesmo que ainda em pequeno número, representantes que carregaram consigo pautas identitárias foram eleitos pelo Partido Democrata, o que leva a discussão para outro ponto: uma vez eleitos conseguirão implementar suas demandas? Isso será um contraponto forte o suficiente para que se recupere as regras democráticas enfraquecidas com a eleição de Trump?

A eleição de Alexandrio Ocasio-Cortez traz elementos para que esse debate tenha continuidade nos próximos anos. Mulher mais jovem a ocupar uma cadeira 
de deputada no Congresso, descendente de porto-riquenhos e socialista, OcasioCortez deixa bem claro a todo momento os demarcadores sociais que a definem e que formam sua perspectiva social. Eleita aos 28 anos, a deputada faz parte da geração denominada 'millennial'e, apesar de não fazer parte da política tradicional, até mesmo porque mulheres com as características acima mencionadas ainda não fazem parte do establishment, tem um histórico de militância política dentro da sua comunidade, além de formação superior em áreas relacionadas. Pode ser considerada uma outsider, mas de forma diferente ao que o termo é associado a Trump, por exemplo. Outro ponto em comum com o presidente é a forma com que utilizou as redes sociais em sua campanha e continua utilizando durante o mandato, algo que, inclusive, deve ser ressaltado como variável de análise deixada de fora nos dois livros citados. Ao responsabilizarem os partidos pela eleição de Trump, se torna fundamental que se analise como as antigas formas de publicidade eleitoral foram superadas em 2016 e como os partidos não estavam preparados para tal, comunicação 'direta' via twitter e demais redes sociais, além do uso de fake news influenciaram diretamente os resultados e foram utilizados pela campanha de Trump de forma exitosa, apesar de moralmente questionável.. Conseguindo ter mais influência nas redes sociais do que a própria imprensa norte americana, Ocasio-Cortez tem a segunda conta com maior projeção dos EUA, atrás apenas do presidente Trump. Isso faz com que se presuma que de alguma forma sua fala esteja chegando nas pessoas.

Sendo assim, contrariando ao que foi dito por Mark Lilla e tirando o foco dos meios tradicionais como assim fizeram Levitsky e Ziblatt, trazer um discurso esquerdista e pró-imigração, vir de uma área desfavorecida como o Bronx, ter uma equipe de menos de 20 funcionários e um orçamento minúsculo, não foram impeditivos para que Ocasio-Cortez tenha derrotado um dos congressistas mais poderosos de Washington nas primárias, Joseph Crowley e Anthony Pappas nas legislativas, numa votação expressiva e que uniu diversos segmentos da população. Como propostas, Ocasio-Cortez conseguiu criar uma narrativa que alia as políticas identitárias com os outros temas que afligem a população que representa. Ao mesmo tempo que defende a diminuição da desigualdade de gênero, sendo ela um exemplo de mudança e ocupação de espaços públicos com poderes decisórios, faz vídeos para seu Instagram mostrando sua rotina e viraliza seus discursos mais importantes, a congressista ocupa o Comitê de Serviços Financeiros do Congresso, colocando como prioridade resolver a crise dos empréstimos estudantis, além de defender a taxação de grandes fortunas, algo com respaldo entre os eleitores, por exemplo.

Falar de Ocasio-Cortez e do que ela representa como possibilidade de sobrevida da democracia, implica em dizer que existe um novo momento político que se impõe, não à toa os três principais grupos de eleitores que crescem nos EUA são de mulheres, jovens e não brancos e se identificam com o Partido Democrata. Portanto, é preciso que se busque caminhos institucionais diferentes daqueles traçados pelos autoritários, porém, com a consciência de que as normas anteriores eram pautadas por exclusão de 
uma parte significativa da população. Para que a democracia volte a ser sólida, com regras que funcionem, é preciso fazer com que seja pautada por igualdade social e diversidade étnica. No mundo moderno e em galáxias distantes ${ }^{1}$, não é mais possível que se perca a liberdade (e a democracia) em meio a estrondosos aplausos, likes e transmissões ao vivo. Democracias precisam estar vivas e se fazendo presentes em políticas reais para pessoas reais.

\footnotetext{
Nota

'Então é assim que a liberdade morre... com um estrondoso aplauso" Senadora Padmé Amidala, Episódio 3 da saga Star Wars "A vingança dos Sith".
}

\section{Referências}

LEVITSKY, S. \& ZIBLATT, D. Como as Democracias Morrem. Tradução Renato Aguiar - 1.ed. - Rio de Janeiro: Zahar, 2018.

LILLA, M. O progressista de ontem e o do amanhã: desafios da democracia liberal no mundo póspolíticas identitárias. Tradução Berilo Vargas - 1.ed. - São Paulo: Companhia das Letras, 2018.

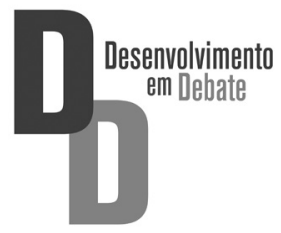




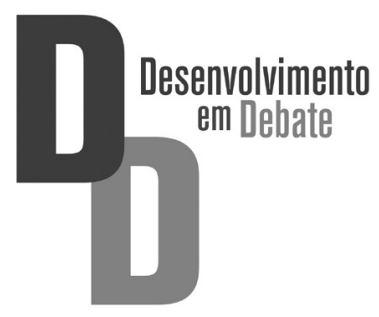

